\title{
Research on the Coordination Characteristics and Interaction Between Innovation-driven Development and Green Development of the Yangtze River Economic Belt in China
}

wei wang

Nanjing University of Posts and Telecommunications

lei zhou

Nanjing University of Posts and Telecommunications

wei chen

Nanjing University of Posts and Telecommunications chao Wu ( chaowu@njupt.edu.cn )

Nanjing University of Posts and Telecommunications

\section{Research Article}

Keywords: innovation-driven development, green development, coupling and coordination, panel model

Posted Date: August 2nd, 2021

DOl: https://doi.org/10.21203/rs.3.rs-673233/v1

License: (c) (i) This work is licensed under a Creative Commons Attribution 4.0 International License. Read Full License

Version of Record: A version of this preprint was published at Environmental Science and Pollution Research on November 19th, 2021. See the published version at https://doi.org/10.1007/s11356-02117470-x. 
Research on the coordination characteristics and interaction between innovation-driven development and green development of the Yangtze River Economic Belt in China Wei Wang ${ }^{1,2}$, Lei Zhou ${ }^{1,2}$, Wei Chen ${ }^{1,2}$, Chao Wu ${ }^{1,2, *}$

1 School of Geographic and Biologic Information, Nanjing University of Posts and Telecommunications, Nanjing 210023, China;

2 Smart Health Big Data Analysis and Location Services Engineering Lab of Jiangsu Province, Nanjing University of Posts and Telecommunications, Nanjing 210023, China

* Author to whom correspondence should be addressed; E-mail: chaowu@njupt.edu.cn; Abstract: Innovation-driven development and green development are both important ways to achieve regional sustainable development. Many studies have focused on innovation-driven dynamic factors and green development impact factors, yet most have paid little attention to the relationship between the two types of factors. This study considers the innovation-driven development and green development evaluation systems of 130 cities in the Yangtze River Economic Belt. Through expert group evaluation, the three dimensions of green production, green life and green ecology are selected to represent the green development index. Innovation input, innovation performance, and innovation potential reflect the innovation-driven development index. The entropy TOPSIS method is used to measure the innovation-driven development index and the green development index of 130 cities in the Yangtze River Economic Belt. Then, a coupling coordination evaluation model and a spatiotemporal heterogeneity analysis model are constructed to discuss the coupling coordination index of regional innovation-driven development and green development in the Yangtze River Economic Belt and to determine its temporal and spatial distribution characteristics. Finally, we choose a spatial panel regression model to explore the relationship between the innovation-driven development index and the green development index of the Yangtze River Economic Belt. The research results show that there is a significant difference between the innovation-driven development index and the green development index of the 130 cities in the Yangtze River Economic Belt in terms of the temporal and spatial distribution. The coordination index of the two has an imbalanced distribution feature, and there is a significant direct or indirect relationship between the two structural indicators in a mathematical sense. This 
study enhances the academic community's understanding of the interaction between innovation-driven development and green development, provides scientifically based support for green development, offers guidance for the implementation of innovation capabilities, and ultimately supports a policy design facilitating regional sustainable development.

Keywords: innovation-driven development; green development; coupling and coordination; panel model

Wei Wang wangwei89@njupt.edu.cn

Lei Zhourzhoulei@njupt.edu.cn

Wei Chen_chen_wei@njupt.edu.cn

WuChaorchaowu@njupt.edu.cn

\section{Introduction}

Innovation-driven development is an important development method for the world economy in the 21 st century. It promotes the transformation and development of the economy from a focus on resource agglomeration and environmental pollution to a focus on resource-saving and environmentally friendly production (Yang and Huang 2019). Innovation-driven development leads to the transformation from the traditional economy, which relies on resource input to promote economic growth, to an economy that relies on scientific and technological changes and labour productivity increases to promote the two-way improvement of the economy in terms of quantity and quality. Most innovation-driven studies focus on innovation-driven economic development methods, paths, and effects, and they rarely consider innovation-driven impact factors. The analysis of the relationship between impact factors on innovation is conducive to further improving the regional innovation level and optimizing innovation-driven performance (Yang and Yan 2019).

Green development is an important approach to regional sustainable development and the main means to solve problems linked to economic development, resources and environment in the 21 st century (Zhao et al. 2010). While promoting the further improvement of the regional economy, green development needs to consider the sustainable use of resources and the improvement of environmental protection quality. The current academic research on green development mainly focuses on the evaluation of the level of green development, the action mechanism and implementation approaches to environmental factors, while the research on the relationship between green development and the driving factors of green development is relatively insufficient. This paper studies the interaction between green development and innovation from the perspective 
of innovation-driven development, aiming to promote a virtuous cycle of innovation-driven, green economic development and provide a new impetus for regional green development.

Innovation-driven development is one of the important driving forces of regional green economic development. The improvement in the green development level feeds back to the supply of innovation-driven factors, and there is an interactive relationship between the two factors under spatiotemporal constraints (Feng and Chen 2018). Both innovation-driven development and green development are composed of complex elements, and the synergistic mechanism between them is reflected in the interaction between elements and in the interaction between elements and the whole. However, the existing literature studies on innovation-driven development and green development are limited to the general relationship between innovation-driven development and green development (Chen et al. 2016a) and lack local understanding. Only by deeply analysing the local and overall relationship between innovation-driven indicators and the green development index can we implement a specific path supporting the synergetic relationship between innovation-driven development and green development.

Therefore, by comprehensively measuring the innovation-driven development index and green development index in the case of the Yangtze River Economic Belt, this article uses the coupling coordination model to explore the coordinated development of the two spatiotemporal patterns and finally analyses the spatial mechanism of the innovation-driven development index and the green development index through the spatial panel model. This effort provides a basic reference for the innovation-driven model and the green development model of regional sustainable development and promotes the further expansion of the research paradigm of regional sustainable development.

\section{Literature review}

\subsection{Innovation-driven development}

Innovation-driven development relies on the social and economic benefits brought by scientific and technological innovation to realize the intensive growth mode, and the core aim is to improve the productivity of production factors by using technological change (Alheet and Hamdan 2020; Laužikas and Dailydaite 2014). In the 21st century, innovation is the primary driving force for world economic development, a strategic support for building a modern economic system, and the only way to achieve high-quality development (Cao et al. 2019). The academic research on 
innovation-driven development has a long history. The research focus has been extended from the initial productivity improvement driving economic development to recent changes in production methods and production technologies that have brought economic growth, resource conservation, environmental protection and other multidimensional benefits, and the connotations of innovation-driven development have been constantly enriched (Calignano and Trippl 2020; De Marchi 2012; Mensah et al. 2018; Yan et al. 2018). Second, in terms of evaluating the innovation-driven index, education level or productivity level has taken as the core index of the innovation-driven index in the last century. Recently, result assessment indicators, such as innovation performance, have been added, and the evaluation system has gradually tended to focus on comprehensiveness, integrity and fairness (Abdelkafi and Pero 2018; Fei et al. 2020; Zhang and Li 2020).

\subsection{Green development}

Green development is currently the best form of social and economic development, reflecting the harmonious symbiosis between human society and the natural environment (Chen et al. 2019). From ancient times to the present, the survival and development of human beings have been closely related to the natural environment, and human production and lifestyles have led to profound changes in the natural environment. The focus on green development in academic studies started with the industrial revolution. With the rapid development of industry, the earth's environment has been constantly deteriorating, and the living space of human beings is threatened. Therefore, the concept of green development has attracted the attention of all humankind (Song et al. 2016). Green development is a harmonious mode of development between humans and the land. Its core significance is to realize the unity of human social development and environmental protection. Scholars have studied the course of green development, from the reduction of the discharge of industrial wastewater, waste gas, and waste residue to the transformation of production methods (Burnett et al. 2013), and studies of the connotation and extension of green development are gradually expanding from the main focus on industrial production to the integrated development of production, life and ecology (Craig 2018; He et al. 2019; Yuan et al. 2020). Currently, scholars consider how to achieve a high-quality green development mode and what social, economic and ecological benefits are generated by green development (Fan et al. 2019; Li and Wu 2017; Wang and Shao 2019). 


\subsection{Innovation-driven development and green development}

In addition to facing the shortcomings of traditional development, green development requires innovative development methods to achieve the integration and unity of socioeconomic development and ecological environmental protection (Meirun et al. 2021). Innovation-driven development is a technological means to realize the transformation of the development mode. Scholars have studied the relationship between innovation and green development from the perspective of diversified innovations. At the beginning, productivity can be improved to reduce the emission of environmental pollutants, and in this period, the relationship between industrial production and environmental pollution is the main focus of attention ( $\mathrm{Li}$ et al. 2019b). In the middle stage of industrialization, the level of productivity is greatly improved, and the research on innovation-driven development and green development focuses on the role of the improvement in science and technology and the treatment rate of environmental pollution (Chen et al. 2016b; Ghisetti and Quatraro 2017; Shao et al. 2016; Yuan and Xiang 2018; Zhang et al. 2018). In the later stages of industrialization, human material levels are mainly satisfied. The restoration of the ecological environment becomes a new pursuit of human quality of life, and innovation is mainly applied in the field of ecological environment restoration (Chen 2015; Li et al. 2019a; Sotarauta and Suvinen 2019).

\subsection{Current deficiencies and improvements}

Innovation-driven development, green development and their interaction have not received enough attention in the following aspects. (1) Studies on innovation-driven development have focused too much on the analysis of the drivers of results, such as what innovation-driven measures are adopted and what development achievements are obtained, but have placed little emphasis on the influence of various factors on innovation and the interaction between innovation and achievements. This paper intends to elaborate on the relationship between innovation drive and innovation achievement from the three aspects of green life, green ecology and green production. (2) While focusing on the social, economic and ecological benefits of green development, previous studies have neglected the dynamic mechanism of maintaining green development. The sustainable and stable driving force of green development is the power source for realizing the sustainable development of humankind. This paper aims to explore the relationship between green development and driving forces from three aspects: innovation input, innovation performance and 
innovation potential. (3) Academic studies on the relationship between innovation-driven development and green development have paid more attention to the overall connection than to the mechanism of action between the two structures. However, the composition structure is the basis for analysing the mechanism of action between innovation-driven development and green development and the focal point for implementing the optimization path. Therefore, this paper explores the contribution of details to overall progress by breaking down the components of innovation-driven development and green development.

\section{Analysis framework}

The above literature review shows that there is a significant direct or indirect relationship between innovation-driven development and green development in different periods, and this mechanism has not been addressed in previous studies. We have established a complete set of evaluation processes, as shown in Figure 1. The evaluation is divided into three parts. The first part is the comprehensive evaluation (blue arrow). Through the construction of an evaluation index system, the innovation-driven development index and green development index are comprehensively evaluated at the functional and structural levels. The second part is the coordination evaluation (red arrow). The coupling coordination model is used to explore the coordination relationship between innovation-driven development and coordinated development, and the spatial agglomeration and anomalous distribution characteristics of the coupling coordination index are analysed based on a spatial-temporal heterogeneity model. The third part is impact assessment (yellow arrow). In this part, the dimension of the interaction between innovation-driven and green development is reduced to the level of specific indicators, and the positive and negative properties and the strength of the impact factors of innovation-driven development and green development are explored. Finally, on the basis of the above three research conclusions, the paper proposes policy suggestions to promote regional innovation-driven development and green development. 


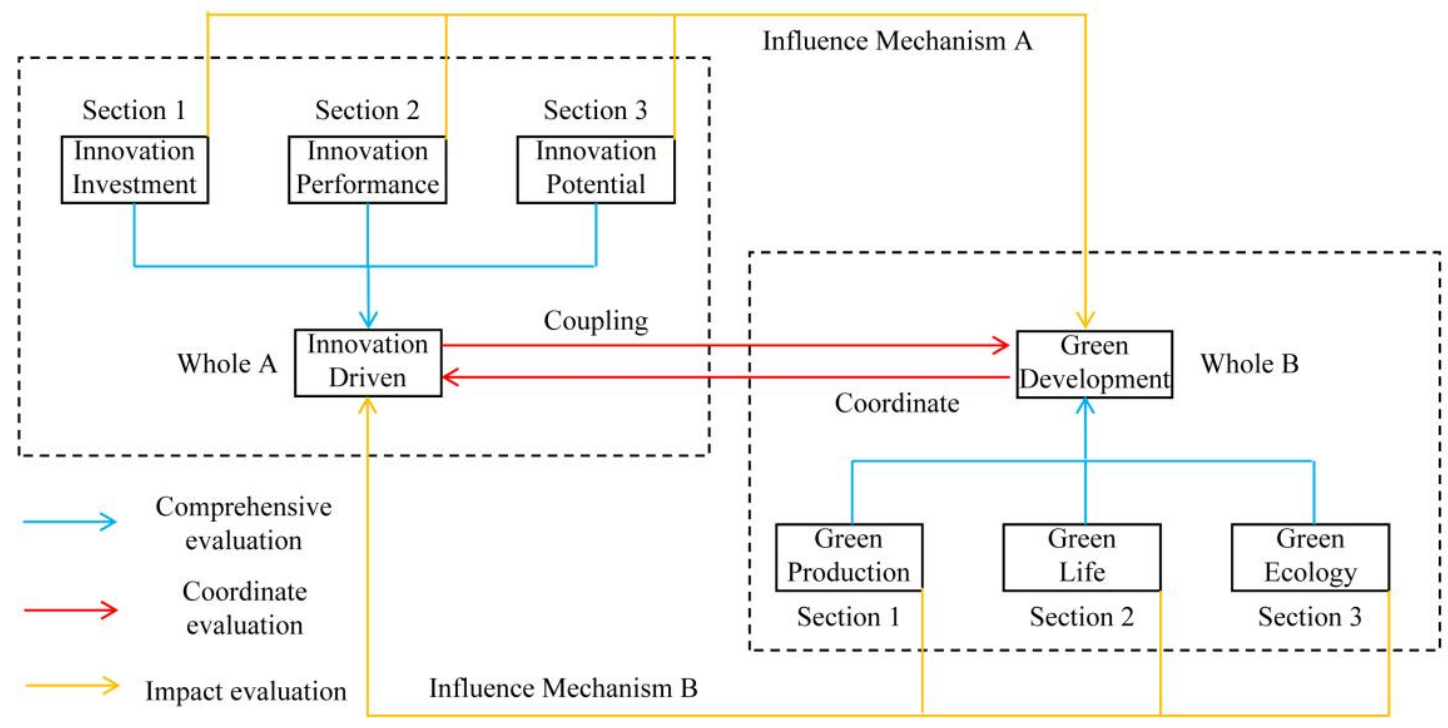

Fig. 1 Coordinated analysis framework of innovation-driven development and green development in the Yangtze River Economic Belt

\section{Data sources and research methods}

\subsection{Study area and dataset}

Located in southern China, the Yangtze River Economic Belt covers 11 provinces and cities (Shanghai, Jiangsu, Zhejiang, Anhui, Jiangxi, Hubei, Hunan, Chongqing, Sichuan, Yunnan and Guizhou) from east to west (Figure 2a). The 11 provinces and cities include 130 cities, such as Shanghai, Nanjing, Wuhan and Chongqing (Figure 2B), covering an area of approximately 2.05 million $\mathrm{km}^{2}$ and representing more than $40 \%$ of China's population and GDP. The Yangtze River Economic Belt is a giant river basin economic belt with the largest population, the largest industrial scale and the most complete urban system in the world.

The statistical data used in this analysis come from the 2004, 2011 and 2018 China City Statistical Yearbooks (http://www.stats.gov.cn/tjsj/); the administrative division map of the Yangtze River Economic Belt was downloaded and drawn from the standard map service system website of the Ministry of Natural Resources of China (http://bzdt.ch.mnr.gov.cn/) for spatial analysis. 


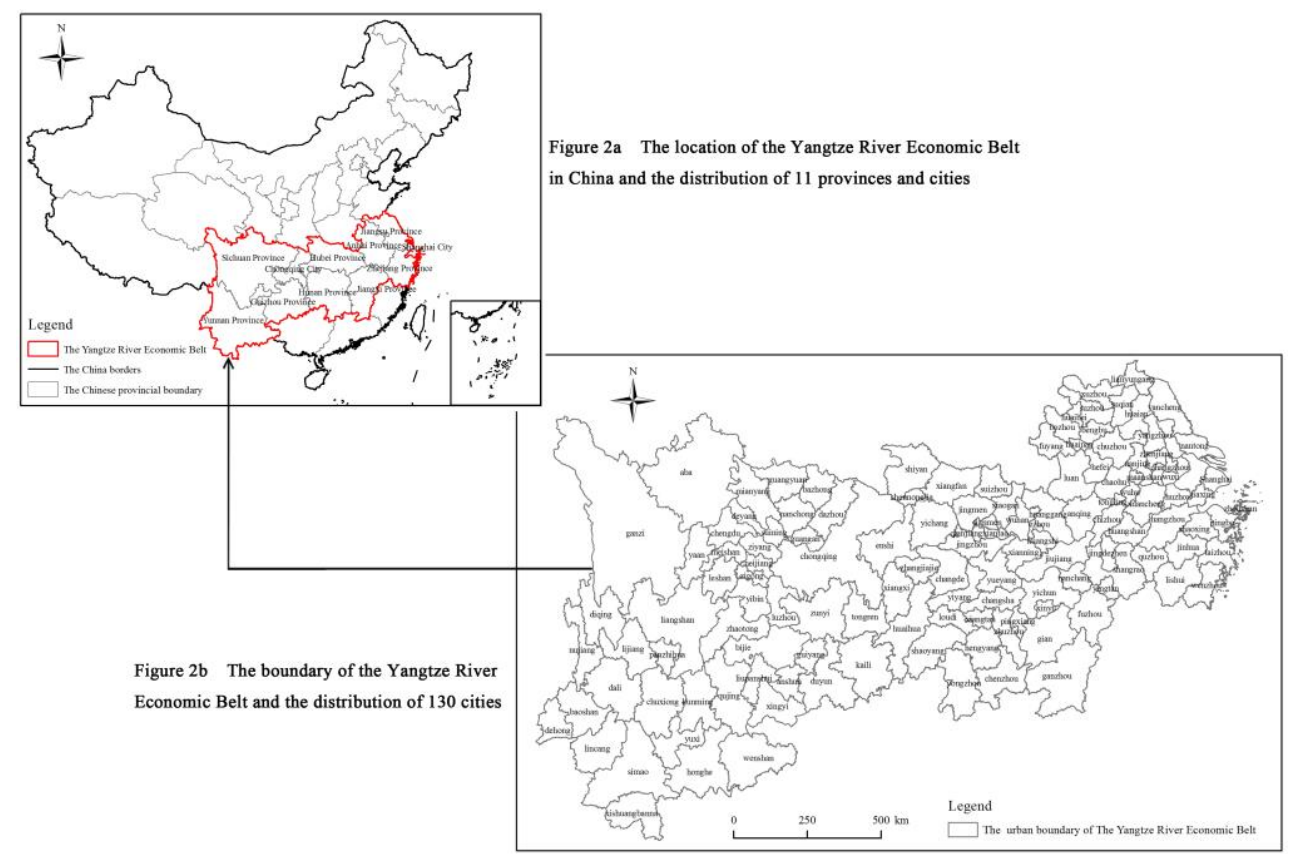

Fig. 2 Location diagram and city composition of the Yangtze River Economic Belt in China

\subsection{Evaluation index system}

Following the principles of representativeness, comparability, hierarchy and operability and referring to relevant literature ( $\mathrm{Li}$ and Song 2016; Sun et al. 2018; Wang et al. 2018; Wang et al. 2019b; Yin et al. 2014) and experts' opinions, an innovation-driven development and green development evaluation system for the Yangtze River Economic Belt was established, as shown in Table 1. The green development index provides a comprehensive evaluation from three levels: green production, green life and green ecology. Production, life and ecology include all the behavioural characteristics relevant to regional socio-economic development and the natural environment. The green behaviour reflected by these three factors can basically represent the level of regional green development. Innovation-driven development refers to the innovation input, innovation performance and potential of the three dimensions, representing the characteristics of innovation activity based on inputs and highlighting innovation as the driving force of the social and economic development of the whole process.

\begin{tabular}{|c|c|c|c|c|c|}
\hline Target & Type & Index & Code & unit & Attribute \\
\hline \multirow{3}{*}{$\begin{array}{l}\text { Green } \\
\text { Development }\end{array}$} & \multirow{3}{*}{$\begin{array}{l}\text { Green } \\
\text { Production }\end{array}$} & $\begin{array}{l}\text { Industrial wastewater discharge per ten thousand yuan of } \\
\text { industrial output value }\end{array}$ & FS & Ten thousand tons & Negative \\
\hline & & $\begin{array}{l}\text { Industrial sulfur dioxide emissions per ten thousand yuan } \\
\text { of industrial output value }\end{array}$ & FL & Ton & Negative \\
\hline & & $\begin{array}{l}\text { Industrial smoke (dust) emissions per ten thousand yuan of } \\
\text { industrial output value }\end{array}$ & FF & Ton & Negative \\
\hline
\end{tabular}




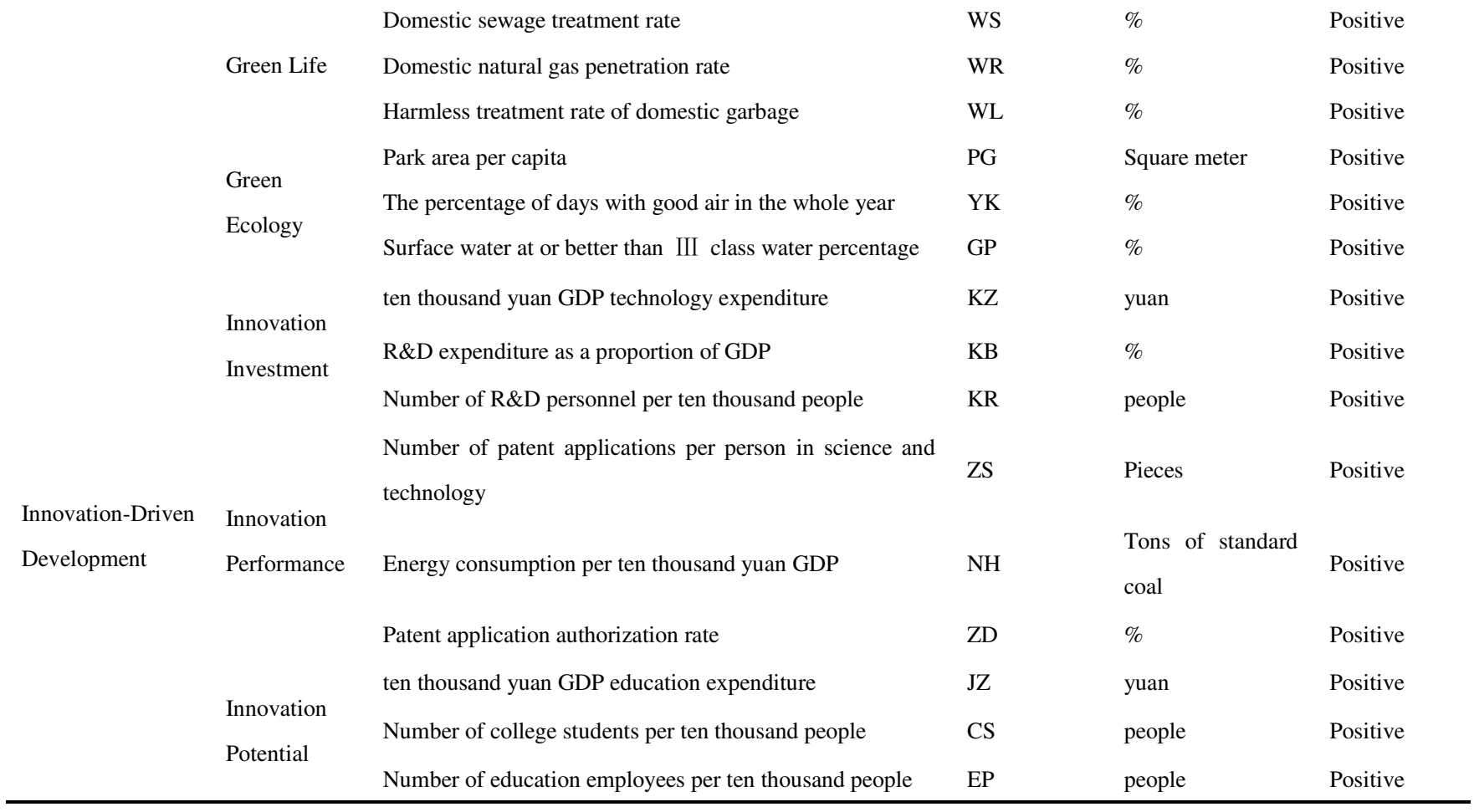

\section{$210 \quad 4.3 \quad$ Research methods}

\section{$211 \quad$ 4.3.1 Comprehensive index evaluation}

212 Considering the difference in weights between the innovation-driven development and green

213 development evaluation indexes, the entropy weight TOPSIS method (Freeman et al. 2015) is

214 applied for comprehensive evaluation and analysis. This method uses the technique of approaching

215 the ideal solution to determine the order of the evaluation objects. The calculation steps are as

216 follows:

217 1) Assume that there are $m$ evaluation objects, and each object has $n$ evaluation indexes.

218 Based on this, the judgement matrix is constructed as Equation (1):

$$
X=\left(x_{i j}\right)_{m \times n}(i=1,2, \cdots, m ; j=1,2, \cdots, n)
$$

2) Standardize the judgement matrix:

The positive index and negative index are shown as follows:

$$
\begin{aligned}
& x_{i j}^{,}=\frac{x_{i j}-\min \left(x_{i j}\right)}{\max \left(x_{i j}\right)-\min \left(x_{i j}\right)} \\
& x_{i j}^{\prime}=\frac{\max \left(x_{i j}\right)-x_{i j}}{\max \left(x_{i j}\right)-\min \left(x_{i j}\right)}
\end{aligned}
$$

3) Calculate information entropy: 


$$
H_{j}=-k \sum_{i=1}^{m} p_{i j} \ln p_{i j}
$$

226

229 where $w_{j} \in[0,1], \sum_{j=1}^{n} w_{j}=1$.

where $p_{i j}=\frac{x_{i j}^{\prime}}{\sum_{i=1}^{m} X_{i j}^{\prime}} ; k=\frac{1}{\ln m}$.

4) Determine the weight of index $j$ :

In the formula, the larger the value of $C_{i}$ is, the better the evaluation object.

\subsubsection{Coordinated development evaluation}

5) Calculate the weighted matrix:

$$
R=\left(r_{i j}\right)_{m \times n}, r_{i j}=w_{j} \times x_{i j}(i=1,2, \cdots, n)
$$

6) Determine the optimal solution $S_{j}^{+}$and worst solution $S_{j}^{-}$:

$$
S_{j}^{+}=\max \left(r_{1 j}, r_{2 j}, \cdots, r_{n j}\right), S_{j}^{-}=\min \left(r_{1 j}, r_{2 j}, \cdots, r_{n j}\right)
$$

7) Calculate the Euclidean distance between the optimal solution and the worst solution of each scheme:

$$
\operatorname{sep}_{i}^{+}=\sqrt{\sum_{j=1}^{n}\left(s_{j}^{+}-r_{i j}\right)^{2}}, \operatorname{sep}_{i}^{-}=\sqrt{\sum_{j=1}^{n}\left(s_{j}^{-}-r_{i j}\right)^{2}}
$$

8) Calculate the comprehensive evaluation index:

$$
C_{i}=\frac{s e p_{i}^{-}}{s e p_{i}^{+}+s e p_{i}^{-}}, C_{i} \in[0,1]
$$

The coupling coordination model in physics is used for reference (Wang et al. 2019a) to establish the coupling coordination evaluation model of innovation-driven development and green development in the Yangtze River Economic Belt, and the calculation formula is as follows:

$$
O U=\left\{\frac{I D A \times G D L}{\left(\frac{I D A+G D L}{2}\right)^{2}}\right\}^{2}
$$


where $O U$ is the coupling degree between innovation-drive development and green development, which is between $[0-1]$; IDA is the innovation-driven composite index; and $G D L$ is the green development composite index. The greater the value of $O U$ is, the stronger the interaction between innovation-driven development and green development; otherwise, the weaker the interaction.

The coupling degree indicates the degree of correlation between the systems but cannot represent the ranking relationship. The coordination degree model (Wang et al. 2019a) is adopted to evaluate the level of coordination between innovation-driven development and green development. The calculation formula is as follows:

$$
X E=\sqrt{O U \times Z H Z}
$$

In the formula, $X E$ is the degree of system coordination and $O U$ is the degree of system coupling. The value of $X E$ ranges from $[0-1]$, and $Z H Z$ is the weighted average of the innovation-driven index and the green development index. The larger the value of $X E$ is, the higher the degree of coordination between innovation-driven development and green development, and vice versa.

\subsubsection{Analysis of influencing factors}

The traditional panel econometric model ignores the effect of spatial parameters on the regression results. This article combines the spatial panel regression model (Wang et al. 2016) and provides regression results that are more consistent with reality by including the relationship between spatial units of the Yangtze River Economic Belt in the econometric model. The spatial lag model, spatial error model and spatial Durbin model are adopted to reflect the spatial interaction relationship between the impact factors on the innovation-driven capacity and the green development level of the Yangtze River Economic Belt. The model can be set as:

$$
G G A Q_{i t}=\beta X_{i t}+\rho \sum_{j=1}^{N} W_{i j} G G A Q_{j t}+\theta \sum_{j=1}^{N} W_{i j} X_{j t}+\mu_{i}
$$

where $G G A Q_{i t}$ is the innovation-driven index or green development index, $i$ and $j$ represent different regions of the Yangtze River Economic Belt, $W_{i j}$ is the spatial matrix of $N \times N, X_{i t}$ regression coefficient of the dependent variable, $\beta$ is the regression coefficient vector of the explanatory variable, $\theta$ is the spatial regression coefficient of the independent variable, and $\varepsilon_{i}$ is the random error term. 


$$
G G A Q_{i t}=\beta X_{i t}+\rho \sum_{j=1}^{N} W_{i j} G G A Q_{j t}+\mu_{i}
$$

When $\lambda \neq 0$ and $\rho=0$, equation 2.13 is transformed into a spatial error model:

$$
G G A Q_{i t}=\beta X_{i t}+\theta \sum_{j=1}^{N} W_{i j} X_{j t}+\mu_{i}
$$

$$
\mu_{i}=\lambda W \mu+\varepsilon_{i}
$$

When $\lambda=0, \rho \neq 0$ and $\theta \neq 0$, equation 2.13 is transformed into a spatial Durbin model:

$$
G G A Q_{i t}=\beta X_{i t}+\rho \sum_{j=1}^{N} W_{i j} G G A Q_{j t}+\theta \sum_{j=1}^{N} W_{i j} X_{j t}+\varepsilon_{i}
$$

The three models are suitable for the analysis of the influencing factors of different mathematical fractals, and the most suitable influencing factor regression model for this study can be determined only after the correlation coefficient test.

\section{Empirical findings}

\subsection{Provincial change characteristics}

Fig. 3 shows the distribution of the green production index, green life index, green ecological index, innovation input index, innovation performance index and innovation potential index, which are components of the green development index and innovation-driven development index, in 11 provinces and cities along the Yangtze River Economic Belt in 2003, 2010 and 2017. The green production index, green living index and innovation performance index show a trend of balanced development, and the gap between the 11 provinces and cities gradually narrows over time. The green ecological index, innovation input index and innovation potential index presents little change, and the spatial distribution characteristics presented a stable and unbalanced distribution.

Fig. 4 shows that the 11 provinces and cities in the Yangtze River Economic Belt have great differences in their innovation-driven indexes, and the spatial pattern is relatively stable over time. The differences in the green development index and comprehensive development index between provinces and cities gradually narrow over time, presenting a more balanced distribution trend.

The coupling relationship and coordination relationship between the innovation-driven index and green development index in 11 provinces and cities along the Yangtze River Economic Belt have a high matching degree (Fig. 5); they are all at a high level, and the differences between 
provinces and cities are small.
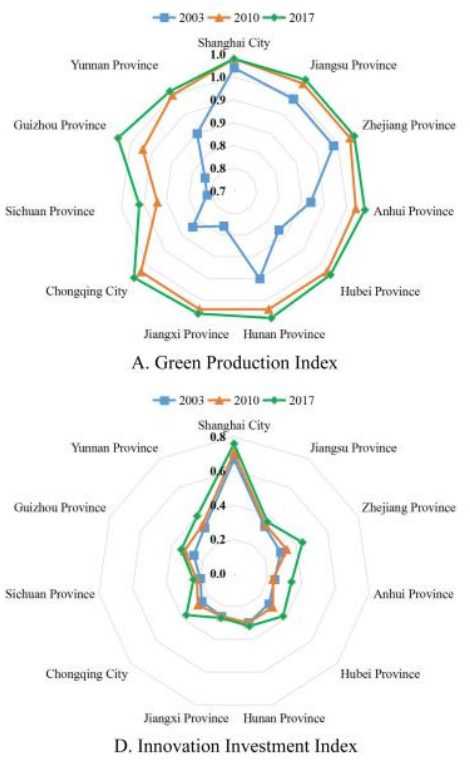
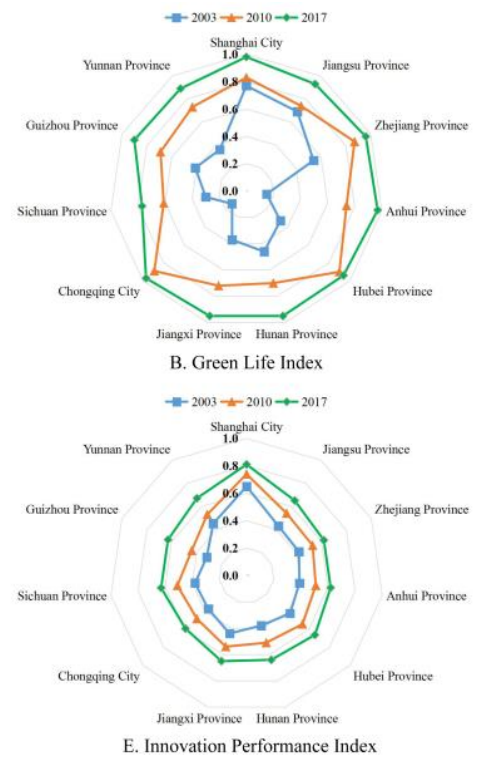

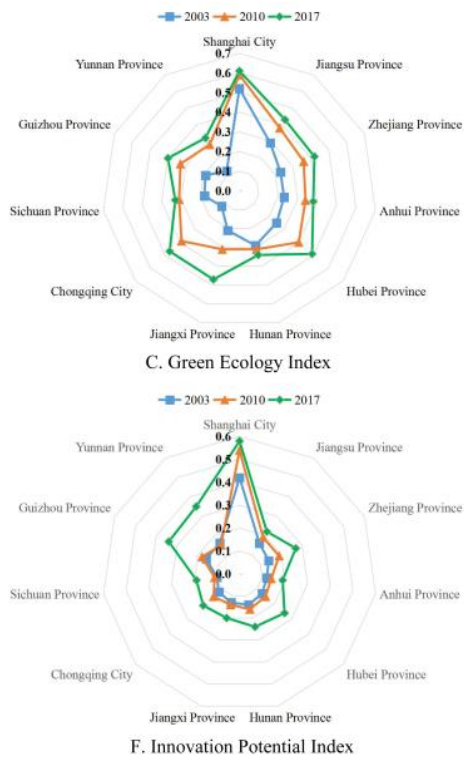

Fig. 3 The distribution of the green production index, green life index, green ecology index, innovation input index, innovation performance index and innovation potential index in 11 provinces and cities of the Yangtze River Economic Belt in 2003, 2010 and 2017
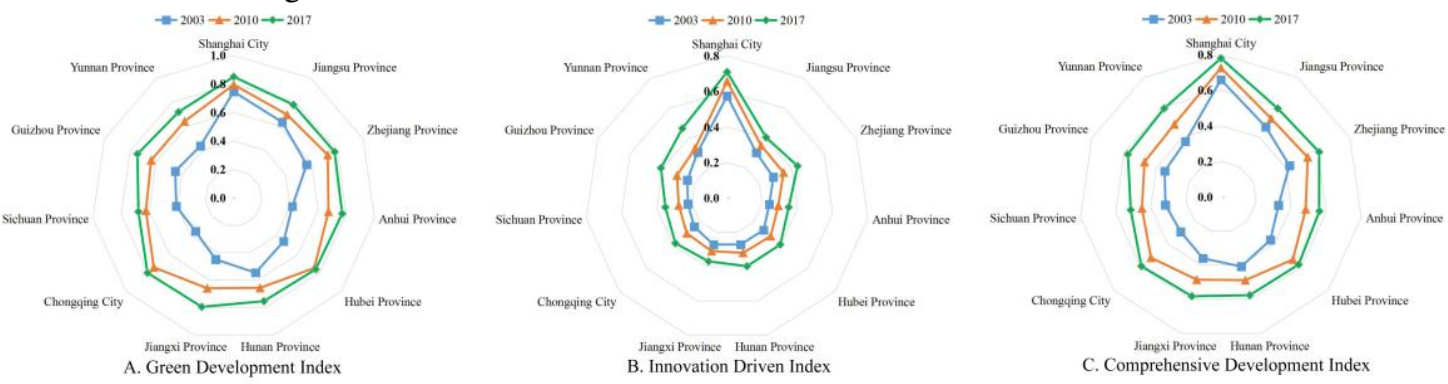

Fig. 4 The distribution of the innovation-driven index, green development index and comprehensive development index of 11 provinces and cities in the Yangtze River Economic Belt in 2003, 2010 and 2017

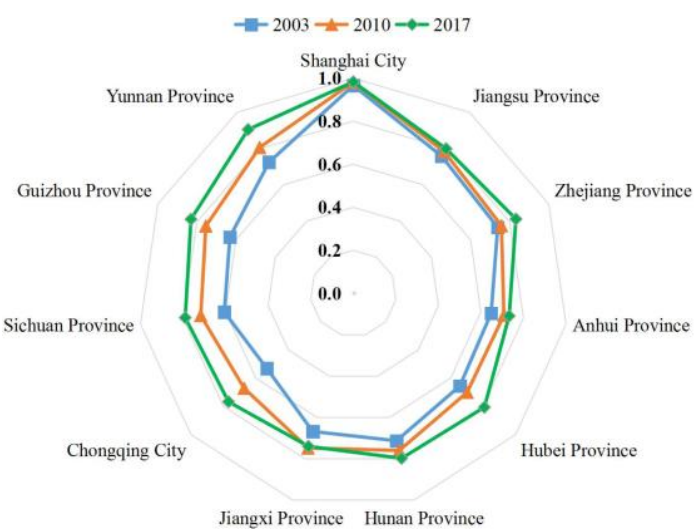

Jiangxi Province Hunan Province
A. Coupling Development Index

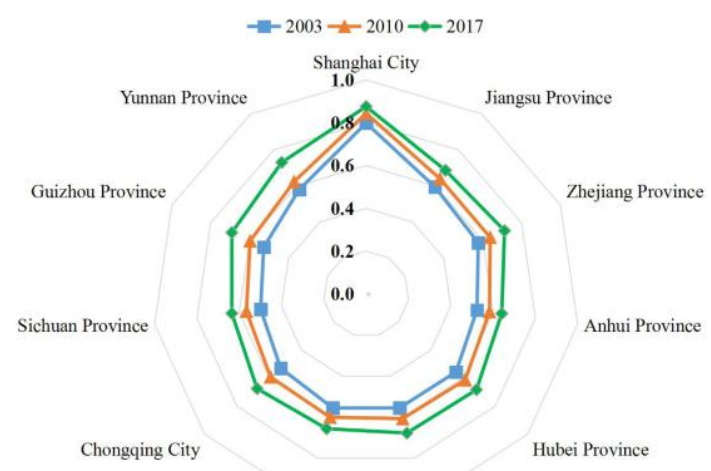

Jiangxi Province Hunan Province

B. Coordinated Development Index

Fig. 5 Coupling coordination index distribution of green development and innovation drive in 11 provinces and cities along the Yangtze River Economic Belt in 2003, 2010 and 2017

\subsection{Urban change characteristics}

Cities with a high index value tend to form high-value planar areas, while cities with a low 
index tend to form low-value agglomeration areas. As shown in Figure 6, the spatial distribution of the innovation-driven index of 130 cities in the Yangtze River Economic Belt in 2003, 2010 and 2017 show significant differences. The high-value areas of the innovation-driven index are distributed in a point-like form, and the low value area gradually expands.

Compared with the innovation-driven index, the green development index in the Yangtze River Economic Belt has a strong high-value agglomeration feature in terms the temporal and spatial distribution. As shown in Figure 7, the high-value area of the green development index gradually expands from east to west, while the low-value area gradually shrinks.

Figure 8 shows the spatial distribution characteristics of the coordination index of innovation-driven development and green development. The high values of the coordination index are distributed in central cities, such as provincial capitals, while the low-value areas show an overall expanding trend.
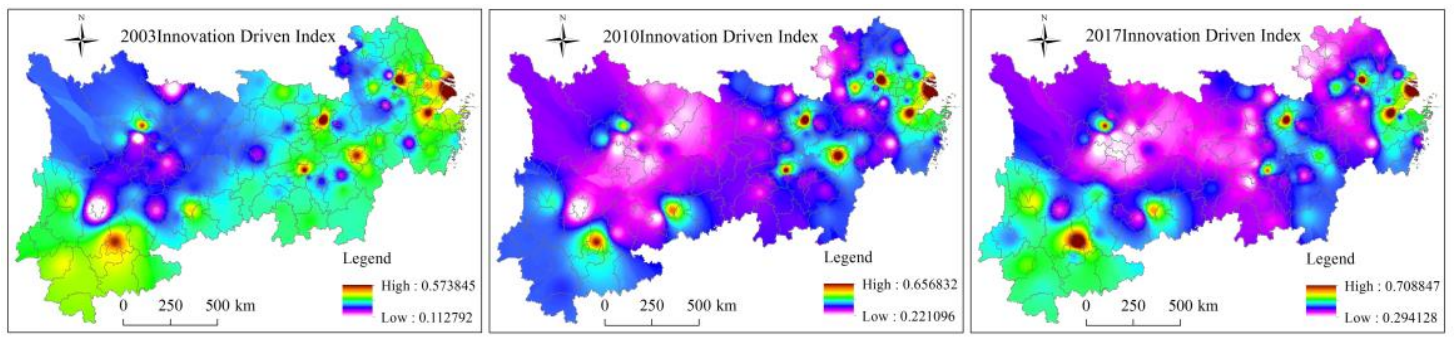

Fig. 6 Spatial distribution of the innovation-driven indexes of 130 cities in the Yangtze River

Economic Belt in 2003, 2010 and 2017
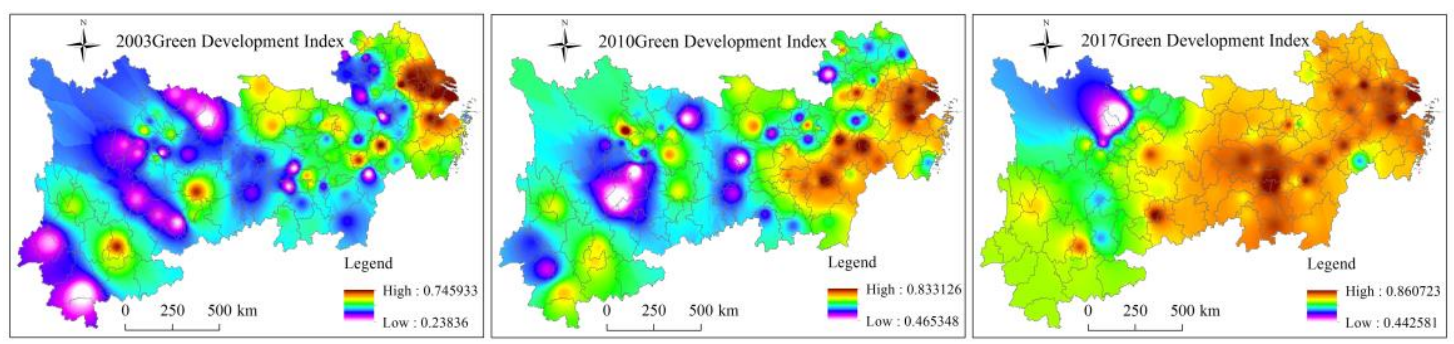

Fig. 7 Spatial distribution of the green development indexes of 130 cities in the Yangtze River Economic Belt in 2003, 2010 and 2017
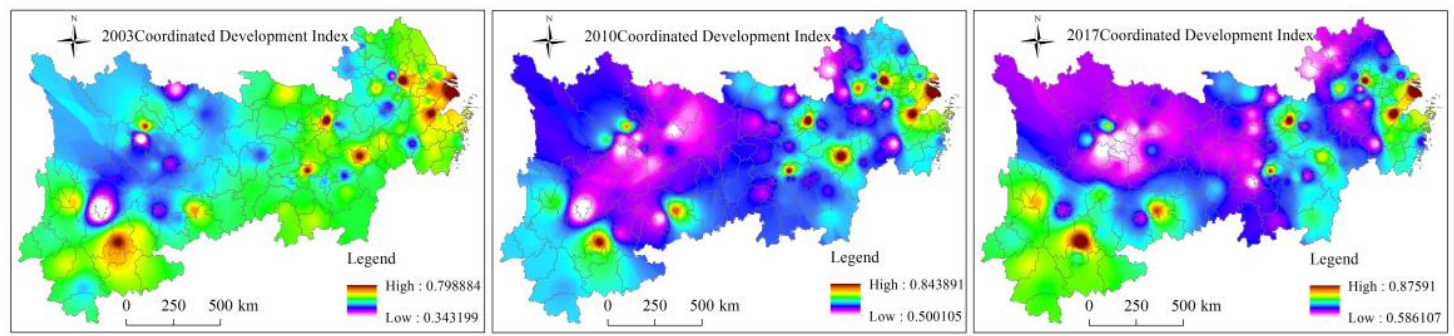

Fig. 8 Spatial distribution of the innovation-driven development and green development coordination indexes of 130 cities in the Yangtze River Economic Belt in 2003, 2010 and 2017 


\subsection{Spatial heterogeneity analysis}

To solve the problem of regional integration development and balanced distribution, it is important to use spatial heterogeneity analysis as a tool to determine the abnormal value of spatial distribution. As shown in Table 2, the global autocorrelation indexes of the innovation-driven development index, green development index and coordinated development index of the Yangtze River Economic Belt in 2003, 2010 and 2017 are all positive, indicating that these indexes have positive clustering characteristics in terms of their spatial distribution, and all pass the significance test at the 5\% level, indicating that the results of spatial heterogeneity analysis are credible.

As shown in Figure 9, the clusters with a high innovation-driven development index are distributed in the eastern cities. The low-high cluster city is Chuzhou, compared with nearby Nanjing. The high-low clusters include Wuhan, the capital city of Hubei Province, and Chengdu, the capital city of Sichuan Province. The surrounding areas of the low-low clusters are all nonsignificant areas, which are evenly distributed in the central and western regions of the Yangtze River Economic Belt.

The spatial heterogeneity distribution of the green development index is similar to that of innovation-driven development. As shown in Figure 10, many high-high clusters are distributed around Shanghai. Only Chengdu, Sichuan Province, remains in the high-low cluster. The low-low clusters are still distributed in the middle and western regions of the Yangtze River Economic Belt.

The spatial distribution characteristics of the coordinated development index are significantly different from those of the green development index and innovation-driven development index, and the outliers are mostly distributed in point-shaped form (Figure 11). The high-high cluster is still dominated by Shanghai and its surrounding areas. The high-low clusters are the provincial capitals of the central and western provinces of the Yangtze River Economic Belt, and the low-low clusters are distributed around them. The low-high clusters are distributed around the high-high clusters.

Table 2 Global autocorrelation test

\begin{tabular}{llllll}
\hline & I Index & Expectation Index & Variance & Z Score & P Value \\
\hline 2003 Green Development Index & 0.4531 & -0.0093 & 0.0042 & 7.1589 & 0.0000 \\
& 0.2649 & -0.0093 & 0.0042 & 4.2541 & 0.0000 \\
2010 Green Development Index & 0.5616 & -0.0093 & 0.0038 & 9.2172 & 0.0000 \\
2017 Green Development Index & 0.0839 & -0.0093 & 0.0039 & 1.8912 & 0.0359
\end{tabular}


2010 Innovation-Driven Development Index

0.1379

$-0.0093$

0.0039

2.3649

0.0179

2017 Innovation-Driven Development Index

0.1381

$-0.0093$

0.0041

2.3342

0.0196

2003 Coordinated Development Index

0.1147

$-0.0093$

$0.0039 \quad 1.9572 \quad 0.0503$

2010 Coordinated Development Index

0.1782

$-0.0093$

$0.0039 \quad 2.9595$

0.0031

2017 Coordinated Development Index

0.2176

$-0.0093$

0.0041

$3.5596 \quad 0.0000$

Fig. 9 LISA distribution of the innovation drive indexes of 130 cities in the Yangtze River Economic
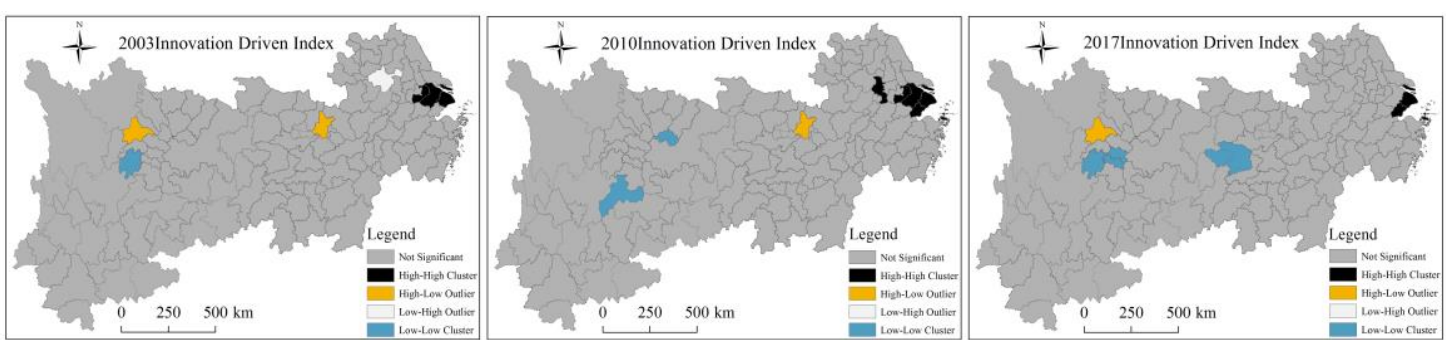

Belt in 2003, 2010 and 2017
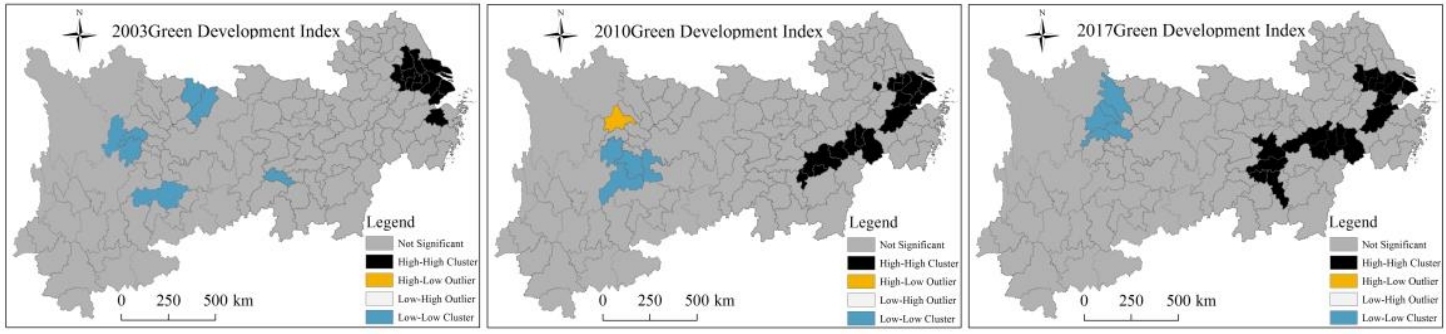

Fig. 10 LISA distribution of the green development indexes of 130 cities in the Yangtze River

Economic Belt in 2003, 2010 and 2017
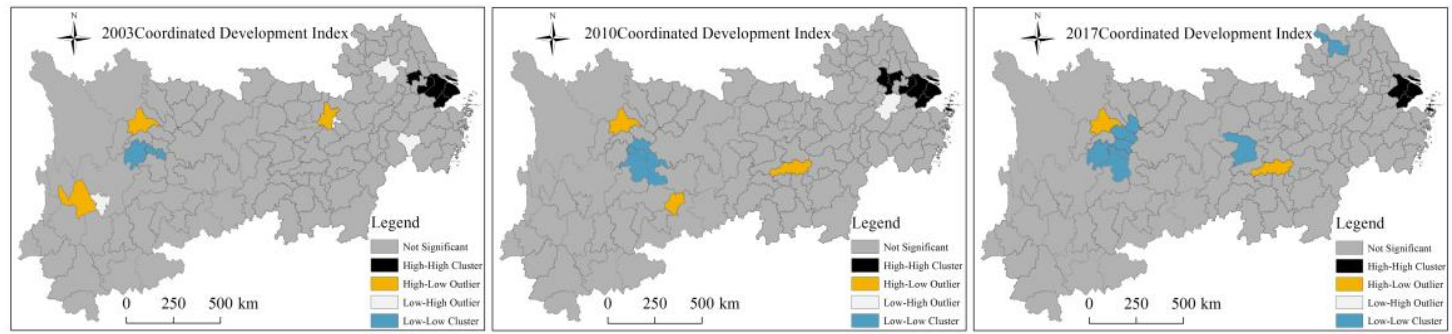

Fig. 11 LISA distribution of the innovation-driven development and green development coordination indexes of 130 cities in the Yangtze River Economic Belt in 2003, 2010 and 2017

\subsection{Influencing mechanism analysis}

The above analysis shows that the coupling index and the coordination index of innovation-driven development and green development of the Yangtze River Economic Belt have the characteristics of spatial heterogeneity, indicating that different characteristic variables have different influences on the two, and their influence presents spatial variation. Therefore, the spatial panel regression model is used to discuss the interaction between the structure of innovation-driven development and green development in the Yangtze River Economic Belt. Table 4-5 show that the

SDM has a higher $R^{2}$ than the SLM and SEM and that the SDM passes the Hausman test at the 


\begin{tabular}{|c|c|c|c|c|c|c|c|c|c|c|c|c|c|}
\hline & & SLM-FE & & SLM-RE & & SEM-FE & & SEM-RE & & SDM-FE & & SDM-RE & \\
\hline Effect & Variable & $\begin{array}{l}\text { Coefficient } \\
\text { value }\end{array}$ & $\begin{array}{l}\mathrm{P} \\
\text { value }\end{array}$ & $\begin{array}{l}\text { Coefficient } \\
\text { value }\end{array}$ & $\begin{array}{l}\mathrm{P} \\
\text { value }\end{array}$ & $\begin{array}{l}\text { Coefficient } \\
\text { value }\end{array}$ & $\begin{array}{l}\mathrm{P} \\
\text { value }\end{array}$ & $\begin{array}{l}\text { Coefficient } \\
\text { value }\end{array}$ & $\begin{array}{l}\mathrm{P} \\
\text { value }\end{array}$ & $\begin{array}{l}\text { Coefficient } \\
\text { value }\end{array}$ & $\begin{array}{l}\mathrm{P} \\
\text { value }\end{array}$ & $\begin{array}{l}\text { Coefficient } \\
\text { value }\end{array}$ & $\begin{array}{l}\mathrm{P} \\
\text { value }\end{array}$ \\
\hline \multirow{5}{*}{$\begin{array}{l}\text { Direct } \\
\text { effect }\end{array}$} & $\operatorname{lnKZ}$ & $0.177 * * *$ & 0.000 & $0.170^{* * *}$ & 0.000 & $0.205^{* * *}$ & 0.00 & $0.198 * * *$ & 0.000 & $0.074 * * *$ & 0.000 & $0.069^{* * *}$ & 0.000 \\
\hline & $\ln K B$ & 0.061 & 0.122 & 0.038 & 0.204 & 0.031 & 0.41 & $0.076^{* * *}$ & 0.005 & $0.232^{* * *}$ & 0.001 & 0.022 & 0.636 \\
\hline & $\ln K R$ & $0.191^{* * *}$ & 0.000 & $0.182 * * *$ & 0.000 & $0.075^{* * *}$ & 0.00 & $0.068^{* * *}$ & 0.000 & $0.283^{* * *}$ & 0.000 & $0.076^{* * *}$ & 0.000 \\
\hline & $\operatorname{lnZS}$ & $0.083 * *$ & 0.020 & $0.074 * * *$ & 0.007 & $0.064 *$ & 0.05 & $0.073 * * *$ & 0.004 & $0.062 *$ & 0.055 & 0.059 ** & 0.046 \\
\hline & $\operatorname{lnNH}$ & $-0.105 * *$ & 0.003 & $-0.103 * * *$ & 0.004 & $-0.134 * * *$ & 0.00 & $-0.125^{* * * *}$ & 0.000 & $-0.107 * * *$ & 0.000 & -0.106 *** & 0.001 \\
\hline
\end{tabular}
results of the fixed-effect SDM in Tables 3-4.

\subsubsection{The innovation-driven impact on green development}

The results in Table 3 show that the proportion of R\&D investment in GDP (KB), the number of $R \& D$ personnel per ten thousand people $(K R)$, the education expenditure per ten thousand yuan of GDP (JZ) and the number of education practitioners per ten thousand people (EP) all have a significant positive impact on the regional green development index. The two indicators, the proportion of R\&D investment in GDP and the number of R\&D personnel per ten thousand people, have an intermediary effect on the region but no significant effect on the green development of neighbouring areas. Education expenditure per ten thousand GDP and the number of educated employees per ten thousand GDP have not only a positive effect on the level of green development in this region but also a positive correlation with neighbouring regions.

\subsubsection{Green development feeds back into innovation-driven development}

Table 4 shows that there is a significant interaction between the innovation drive development index and the gross value of industrial wastewater emissions per ten thousand yuan of industrial output (FS), the hazard-free treatment rate of waste (WL), days with good air quality (YK) and the ratio of surface water at or better than class III (GP). The two indicators of wastewater emissions per ten thousand yuan of industrial output and the hazard-free treatment rate of waste have direct effects only on the regional innovation drive development index, with high correlation coefficients. Wastewater emissions per ten thousand yuan of industrial output is negatively related with the regional innovation drive development index and the hazard-free treatment rate of domestic waste is positively. There is a significant positive correlation between the two indicators of the proportion of days with good air quality in the whole year and the proportion of surface water at least or better than type III and the innovation drive development index of the region and adjacent regions.

Table 3 Panel model regression results of green development impact factors 


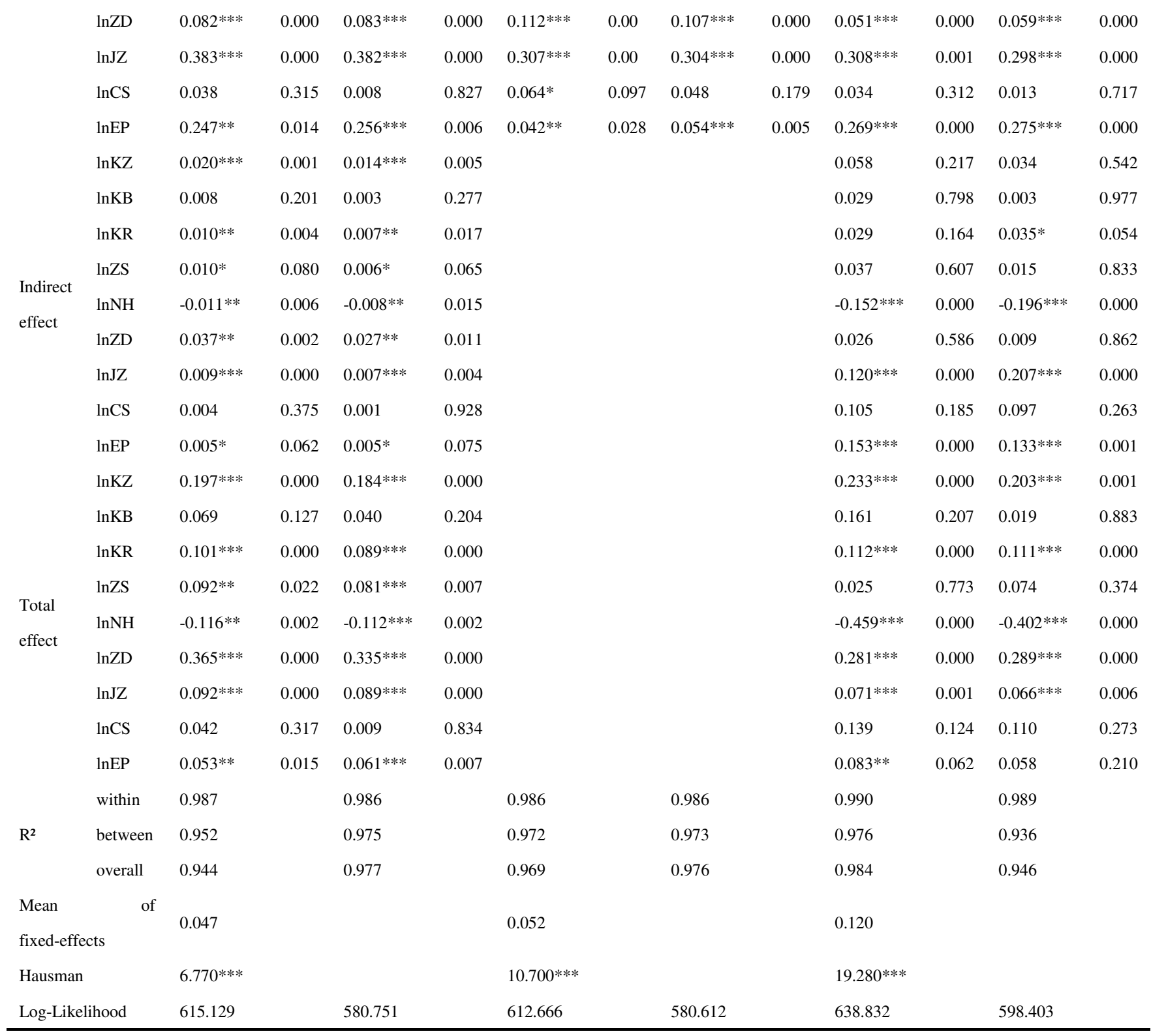

Note: $* * *, * * *$ indicate the significance level of $10 \%, 5 \%$, and $1 \%$.

407 Table 4 Panel model regression results of innovation-driven development impact factors

\begin{tabular}{|c|c|c|c|c|c|c|c|c|c|c|c|c|c|}
\hline & & SLM-FE & & SLM-RE & & SEM-FE & & SEM-RE & & SDM-FE & & SDM-RE & \\
\hline Effect & Variable & $\begin{array}{l}\text { Coefficient } \\
\text { value }\end{array}$ & $\begin{array}{l}P \\
\text { value }\end{array}$ & $\begin{array}{l}\text { Coefficient } \\
\text { value }\end{array}$ & $\begin{array}{l}P \\
\text { value }\end{array}$ & $\begin{array}{l}\text { Coefficient } \\
\text { value }\end{array}$ & $\begin{array}{l}P \\
\text { value }\end{array}$ & $\begin{array}{l}\text { Coefficient } \\
\text { value }\end{array}$ & $\begin{array}{l}\mathrm{P} \\
\text { value }\end{array}$ & $\begin{array}{l}\text { Coefficient } \\
\text { value }\end{array}$ & $\begin{array}{l}\mathrm{P} \\
\text { value }\end{array}$ & $\begin{array}{l}\text { Coefficient } \\
\text { value }\end{array}$ & $\begin{array}{l}\mathrm{P} \\
\text { value }\end{array}$ \\
\hline \multirow{9}{*}{$\begin{array}{l}\text { Direct } \\
\text { effect }\end{array}$} & $\ln F S$ & $-0.146 * * *$ & 0.001 & $-1.042 * * *$ & 0.003 & $-0.133 * *$ & 0.011 & $-0.130 * *$ & 0.025 & $-0.149 * * *$ & 0.001 & $-0.145 * * *$ & 0.002 \\
\hline & $\operatorname{lnFL}$ & -0.020 & 0.242 & -0.015 & 0.418 & -0.011 & 0.568 & -0.005 & 0.817 & -0.019 & 0.340 & -0.013 & 0.543 \\
\hline & $\operatorname{lnFF}$ & $-0.085 * * *$ & 0.000 & $-0.091 * * *$ & 0.000 & $-0.097 * * *$ & 0.000 & $-0.103 * * *$ & 0.000 & $-0.071 * * *$ & 0.000 & $-0.079 * * *$ & 0.000 \\
\hline & $\operatorname{lnWS}$ & $0.040^{* * * *}$ & 0.000 & $0.038 * * *$ & 0.000 & $0.046 * * *$ & 0.000 & $0.043 * * *$ & 0.000 & $0.030 * * *$ & 0.000 & $0.030^{* * *}$ & 0.000 \\
\hline & $\operatorname{lnWR}$ & $0.024 * * *$ & 0.010 & $0.025 * * *$ & 0.008 & $0.039 * * *$ & 0.000 & $0.039 * * *$ & 0.000 & $0.016^{* * * *}$ & 0.005 & $0.017 * * *$ & 0.008 \\
\hline & $\operatorname{lnWL}$ & $0.192^{* * * *}$ & 0.000 & $0.185^{* * *}$ & 0.000 & $0.155^{* * * *}$ & 0.000 & $0.152 * * *$ & 0.001 & $0.133^{* * * *}$ & 0.000 & $0.125 * * *$ & 0.000 \\
\hline & $\ln P G$ & 0.011 & 0.421 & 0.010 & 0.457 & 0.010 & 0.454 & 0.010 & 0.477 & 0.016 & 0.325 & 0.015 & 0.370 \\
\hline & $\ln Y K$ & $0.180^{*}$ & 0.092 & $0.195^{* *}$ & 0.050 & 0.086 & 0.116 & $0.105 *$ & 0.064 & $0.180 * * *$ & 0.006 & $0.199 * * *$ & 0.001 \\
\hline & $\operatorname{lnGP}$ & $0.159^{* * *}$ & 0.000 & $0.161 * * *$ & 0.000 & $0.174 * * *$ & 0.000 & $0.174 * * *$ & 0.000 & $0.147 * * *$ & 0.001 & $0.148 * * *$ & 0.001 \\
\hline Indirect & $\ln F S$ & $0.019 * *$ & 0.037 & $0.015^{*}$ & 0.062 & & & & & -0.014 & 0.708 & -0.006 & 0.890 \\
\hline effect & $\operatorname{lnFL}$ & 0.008 & 0.311 & 0.005 & 0.466 & & & & & 0.040 & 0.505 & 0.039 & 0.513 \\
\hline
\end{tabular}




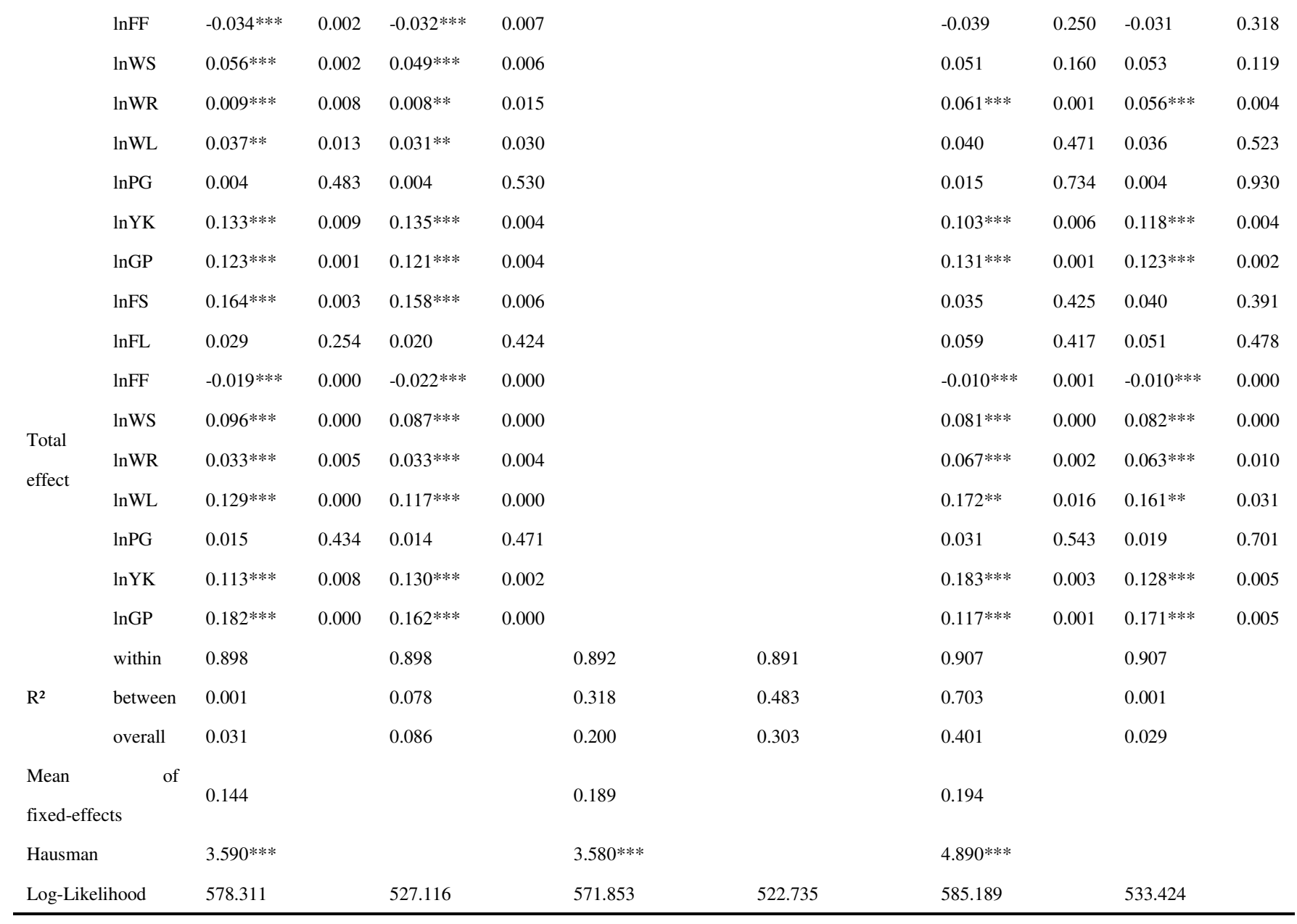

Note: $* * * * * *$ indicate the significance level of $10 \%, 5 \%$, and $1 \%$.

\section{Discussion}

\subsection{The spatial distribution of the innovation-driven development and green} development coordination indexes

This study shows that the spatial distribution of the innovation-driven development and green development coordination indexes in the Yangtze River Economic Belt presents an unbalanced

413 trend and that the differences between cities and regions are gradually increasing, especially

414 between central cities (provincial capitals, municipalities directly under the central government,

415 etc.) and surrounding cities. An increase or decrease in the coordination index reflects an increase

416 or decrease in the cooperation coefficient between innovation-driven development and green

417 development. From the perspective of classification, from 2003 to 2017, the high-value area of the

418 green development index of the Yangtze River Economic Belt shows an expanding trend from the

419 east to the centre, while the high-value area of the innovation-driven development index shows a

420 shrinking trend from the centre to the east. Such spatial distribution characteristics are related to

421 the administrative system with Chinese characteristics. Innovation depends on the investment of 
science and education funds and personnel. Compared with central cities, general cities in the western region have limited science and education resources, which cannot be closely connected with innovation-driven development. The lack of coordination between the two leads to the lack of sustainability and self-generation of regional green development. Therefore, finding the innovation-driven green development path of the general cities of the Yangtze River Economic Belt is a feasible way to support the region's green and sustainable development.

\subsection{Spatial heterogeneity of the innovation-driven development and green development coordination index}

Spatial heterogeneity across regions is a key issue for the coordination between the innovation-driven development and green development of the Yangtze River Economic Belt. According to the above research conclusions, there is significant spatial heterogeneity across regions of the Yangtze River Economic Belt in terms of the innovation drive development index, green development index and coordinated development index from 2003 to 2017. Low-low clusters indicate that the development index values of a region and its surrounding regions are significantly low; such areas are mainly distributed in the central and western regions of the Yangtze River Economic Belt. Compared with the downstream areas, these areas have a low economic development level, a poor innovation atmosphere, and limited green development and therefore form an agglomeration area with low-low clusters. High-high clusters refer to the areas with high development indexes of their own and in the surrounding areas within the Yangtze River Economic Belt. Such areas are concentrated in the eastern region with a high level of economic development, high investment in innovation resources and an interactive and cooperative mechanism between innovation and green development. The coordination index of low-high clusters is significantly lower than that of surrounding areas. Policy mechanisms, such as resource investment, process management and efficiency improvement, should be developed to quickly improve the unfavourable positions of these areas and facilitate the spatial expansion and extension of high-value areas. The coordination index of high-low clusters is significantly higher than that of the surrounding areas. How to link related resources and drive the coordinated development of surrounding areas is the core of improving the overall level of low-low clusters. 

development

The analysis of the impact mechanism is a key step in promoting innovation-driven development and green development. In the interaction between innovation-driven development and green development in the Yangtze River Economic Belt, there are many-to-one and one-to-many relationships between the two impact modes. To improve the level of green development in low-high clusters, it is necessary to increase the proportion of R\&D investment in GDP and increase the number of R\&D personnel per ten thousand people, as both of these indicators have a significant positive impact on the improvement in the level of green development in the region. To improve the green development level of low-low clusters, it is necessary to increase the education expenditure per ten thousand GDP and increase the number of education employees per ten thousand people. Both of these measures not only improve the green development level of their own region but also have a significant impact on the green development level of neighbouring regions, and they are thus suitable for contiguous low-low clusters.

The influencing mechanism of the innovation-driven development index is also improved by differentiation according to the sub-regional types mentioned above. For continuous innovation in the low index areas of low-low clusters, the application of two-way indicators has direct effects and indirect effects, enhancing the overall level of innovation in these clusters. The model results show that indexes such as the proportion of days with good air quality and the ratio of surface water at or better than level III can be effectively improved. For the development of low-high clusters, the indexes with significant effects in individual regions but not neighbouring regions should be selected. The model results highlight the importance of the two indexes of industrial wastewater discharge per ten thousand yuan of industrial output value and the harmless disposal rate of domestic waste. Reducing the industrial wastewater discharge per ten thousand yuan of industrial output value and increasing the harmless treatment rate of domestic waste can effectively improve the innovation-driven development index of low-high clusters.

\subsection{Strengths and limitations}

This study has several advantages. First, the Yangtze River Economic Belt, a pilot area of innovation-driven development and green development in China, is taken as a case to study the coordinated relationship between innovation-driven development and green development. This 
study is representative and can be used as a reference for the development of other regions. Second, by constructing an evaluation index system, we evaluate the innovation-driven development index and green development index in different dimensions, which can comprehensively represent the actual level of evaluation targets. Third, by decomposing the overall and local relationships between innovation-driven development and green development, we can find specific indicators with spatial heterogeneity to support the implementation of countermeasures and suggestions.

Our study has some limitations. First, the study scale of spatial distribution is at the provincial level and the city level, and some characteristic conclusions are drawn. However, some indicators, such as the domestic sewage treatment rate, household garbage harmless treatment rate, and per capita park green area, can be refined to more microscopic research scales, such as the county level and township level, and more detailed research conclusions can be drawn to overcome the spatial limitations of this study. Second, the index data from the China Statistical Yearbook, such as per capita park green area, green coverage rate of built-up areas, science and technology expenditure per ten thousand GDP, and education expenditure per ten thousand GDP, are counted only in municipal districts, and the integrity of the research data needs to be further strengthened. Third, in the chapter on the influencing mechanism, we analyse the action mechanism of specific indicators on the overall development, including the differentiation analysis of both an individual region and adjacent regions. However, some indicators also have differences in the action cycle or even lag effects, which are not extended to the action cycle due to the model limitations. All the above three points need to be addressed in follow-up studies.

\section{Conclusion}

In this paper, the entropy weight TOPSIS method and the coupling coordination model were used to evaluate the coupling coordination relationship between innovation-driven development and green development in the Yangtze River Economic Belt, and the influencing mechanism between the two was explored from the perspective of spatial panel data. In general, the coordination index of innovation-driven development and green development in the 11 provinces and cities of the Yangtze River Economic Belt has a distribution pattern of high in the east and low in the west. The eastern coastal region of the Yangtze River Economic Belt, as the frontier for the land acquisition of foreign enterprises, presents strong coordination between innovation-driven development and green development. The improvement in innovation ability can support 
advancement toward the goal of green development, and green development can optimize the

511 development environment and promote the further improvement in innovation ability. The central

512 and western regions of the Yangtze River Economic Belt are located inland, and their

513 innovation-driven development and green development indexes are both low, indicating that these

514 regions have not formed a well-coordinated relationship. Local influencing factors have

515 significantly heterogeneous effects on the overall development space. This study fills the gap in the

516 literature regarding the interaction mechanism between innovation-driven development and green

517 development in the academic world, and the proposed evaluation index system has a certain

518 universality and significance.

519 Authors' contribution

520 Wei Wang: Conceptualization, Methodology, Software and Writing.

521 Lei Zhou: Visualization, Investigation and Writing.

522 Wei Chen: Writing, Software, Validation.

523 Chao Wu: Writing, Reviewing and Editing.

524 Funding This research was funded by the National Natural Science Foundation of China (No.

525 42001237, 41901326, 42071212); the Philosophy and Social Science Research of Jiangsu Higher

526 Education Institutions (2020SJA0093) and the Natural Science Foundation of Jiangsu Province

527 (BK20190742).

528 Compliance with ethical standards

529 Conflict of interest The author declares that there is no conflict of interest

530 Data availability Not applicable

$531 \quad$ Declarations

532 Ethical approval Not applicable

533 Consent to participate Not applicable

534 Consent to publish Not applicable

535 Competing interests The authors declare that they have no competing interests.

\section{$537 \quad$ References}

538 Abdelkafi, N., \& Pero, M. (2018). Supply chain innovation-driven business models. Business Process

539 Management Journal, 24, 589-608

540 Alheet, A.F., \& Hamdan, Y. (2020). Evaluating innovation-driven economic growth: a case of Jordan.

541 Entrepreneurship and Sustainability Issues, 7, 1790-1802 
Burnett, J.W., Bergstrom, J.C., \& Dorfman, J.H. (2013). A spatial panel data approach to estimating U.S. state-level energy emissions. Energy Economics, 40, 396-404 Calignano, G., \& Trippl, M. (2020). Innovation-Driven or Challenge-Driven Participation in International Energy Innovation Networks? Empirical Evidence from the H2020 Programme. Sustainability, 12

547 Cao, W., Zhang, Y., \& Qian, P. (2019). The Effect of Innovation-Driven Strategy on Green Economic 548 Development in China-An Empirical Study of Smart Cities. International Journal of Environmental 549 Research and Public Health, 16

550 Chen, C., Han, J., \& Fan, P. (2016a). Measuring the Level of Industrial Green Development and 551 Exploring Its Influencing Factors: Empirical Evidence from China's 30 Provinces. Sustainability, 8

552 Chen, L., Zhang, X., He, F., \& Yuan, R. (2019). Regional green development level and its spatial relationship under the constraints of haze in China. Journal of Cleaner Production, 210, 376-387 Chen, S. (2015). The evaluation indicator of ecological development transition in China's regional economy. Ecological Indicators, 51, 42-52 Chen, Y.-S., Chang, T.-W., Lin, C.-Y., Lai, P.-Y., \& Wang, K.-H. (2016b). The Influence of Proactive Green Innovation and Reactive Green Innovation on Green Product Development Performance: The Mediation Role of Green Creativity. Sustainability, 8

559 Craig, M.P.A. (2018). 'Treasury Control' and the British Environmental State: The Political Economy of Green Development Strategy in UK Central Government. New Political Economy, 25, 30-45

De Marchi, V. (2012). Environmental innovation and R\&D cooperation: Empirical evidence from Spanish manufacturing firms. Research Policy, 41, 614-623

Fan, X., Li, X., \& Yin, J. (2019). Impact of environmental tax on green development: A nonlinear dynamical system analysis. PLoS One, 14, e0221264

Fei, R., Cui, A., \& Qin, K. (2020). Can technology R\&D continuously improve green development level in the open economy? Empirical evidence from China's industrial sector. Environ Sci Pollut Res Int, 27, 34052-34066

Feng, Z., \& Chen, W. (2018). Environmental Regulation, Green Innovation, and Industrial Green Development: An Empirical Analysis Based on the Spatial Durbin Model. Sustainability, 10 Freeman, J., Gary Graham, D., \& Chen, T. (2015). Green supplier selection using an AHP-Entropy-TOPSIS framework. Supply Chain Management: An International Journal, 20, 327-340 Ghisetti, C., \& Quatraro, F. (2017). Green Technologies and Environmental Productivity: A Cross-sectoral Analysis of Direct and Indirect Effects in Italian Regions. Ecological Economics, 132, $1-13$

He, L., Zhang, L., Zhong, Z., Wang, D., \& Wang, F. (2019). Green credit, renewable energy investment and green economy development: Empirical analysis based on 150 listed companies of China. Journal of Cleaner Production, 208, 363-372

578 Laužikas, M., \& Dailydaite, S. (2014). Impacts of Social Capital on Transformation from Efficiency To 579 Innovation-Driven Business. Journal of Business Economics and Management, 16, $37-51$

$580 \mathrm{Li}$, B., \& Wu, S. (2017). Effects of local and civil environmental regulation on green total factor productivity in China: A spatial Durbin econometric analysis. Journal of Cleaner Production, 153, 342-353

583 Li, H., He, F., \& Deng, G. (2019a). How does Environmental Regulation Promote Technological 584 Innovation and Green Development? New Evidence from China. Polish Journal of Environmental 585 Studies, 29, 689-702

586 Li, K., \& Song, M. (2016). Green Development Performance in China: A Metafrontier Non-Radial 
Approach. Sustainability, 8

Li, W., Wang, J., Chen, R., Xi, Y., Liu, S.Q., Wu, F., Masoud, M., \& Wu, X. (2019b). Innovation-driven industrial green development: The moderating role of regional factors. Journal of Cleaner Production, $222,344-354$

Meirun, T., Mihardjo, L.W., Haseeb, M., Khan, S.A.R., \& Jermsittiparsert, K. (2021). The dynamics effect of green technology innovation on economic growth and $\mathrm{CO} 2$ emission in Singapore: new evidence from bootstrap ARDL approach. Environ Sci Pollut Res Int, 28, 4184-4194 Mensah, C.N., Long, X., Boamah, K.B., Bediako, I.A., Dauda, L., \& Salman, M. (2018). The effect of innovation on CO2 emissions of OCED countries from 1990 to 2014. Environmental Science and Pollution Research, 25, 29678-29698

Shao, S., Luan, R., Yang, Z., \& Li, C. (2016). Does directed technological change get greener: Empirical evidence from Shanghai's industrial green development transformation. Ecological Indicators, 69, 758-770

Song, M., Guan, Y., Wang, J., \& Zhao, J. (2016). Evaluation of urban industrial ecological transformation in China. Clean Technologies and Environmental Policy, 18, 2649-2662 Sotarauta, M., \& Suvinen, N. (2019). Place leadership and the challenge of transformation: policy platforms and innovation ecosystems in promotion of green growth. European Planning Studies, 27, 1748-1767 Sun, C., Tong, Y., \& Zou, W. (2018). The evolution and a temporal-spatial difference analysis of green development in China. Sustainable Cities and Society, 41, 52-61 Wang, M.-X., Zhao, H.-H., Cui, J.-X., Fan, D., Lv, B., Wang, G., Li, Z.-H., \& Zhou, G.-J. (2018). Evaluating green development level of nine cities within the Pearl River Delta, China. Journal of Cleaner Production, 174, 315-323

610 Wang, Q., Mao, Z., Xian, L., \& Liang, Z. (2019a). A study on the coupling coordination between tourism and the low-carbon city. Asia Pacific Journal of Tourism Research, 24, 550-562

612 Wang, Q., Qu, J., Wang, B., Wang, P., \& Yang, T. (2019b). Green technology innovation development in 613 China in 1990-2015. Sci Total Environ, 696, 134008

614 Wang, X., \& Shao, Q. (2019). Non-linear effects of heterogeneous environmental regulations on green 615 growth in G20 countries: Evidence from panel threshold regression. Science of The Total Environment, $616 \quad 660,1346-1354$

617 Wang, Z., Cheng, Y., Ye, X., \& Wei, Y.H.D. (2016). Analyzing the Space-Time Dynamics of Innovation 618 in China: ESDA and Spatial Panel Approaches. Growth and Change, 47, 111-129

619 Yan, M.-R., Chien, K.-M., Hong, L.-Y., \& Yang, T.-N. (2018). Evaluating the Collaborative Ecosystem 620 for an Innovation-Driven Economy: A Systems Analysis and Case Study of Science Parks. Sustainability, 10 Technology-Driven Business Innovation Ecosystems. Sustainability, 11 Yang, Y., \& Huang, P. (2019). Has the level of green development in the northwestern provinces of China truly improved? A case study of Shaanxi. Sustainable Cities and Society, 51 Yin, K., Wang, R., An, Q., Yao, L., \& Liang, J. (2014). Using eco-efficiency as an indicator for sustainable urban development: A case study of Chinese provincial capital cities. Ecological Indicators, $36,665-671$ Yuan, B., \& Xiang, Q. (2018). Environmental regulation, industrial innovation and green development of Chinese manufacturing: Based on an extended CDM model. Journal of Cleaner Production, 176, 895-908 
633 China: An index based assessment from perspectives of both current performance and historical effort.

634 Journal of Cleaner Production, 250

635 Zhang, J., Chang, Y., Zhang, L., \& Li, D. (2018). Do technological innovations promote urban green 636 development?-A spatial econometric analysis of 105 cities in China. Journal of Cleaner Production, $637 \quad 182,395-403$

638 Zhang, M., \& Li, B. (2020). How to Improve Regional Innovation Quality From the Perspective of 639 Green Development? Findings From Entropy Weight Method and Fuzzy-Set Qualitative Comparative 640 Analysis. IEEE Access, 8, 32575-32586

641 Zhao, M., Tan, L., Zhang, W., Ji, M., Liu, Y., \& Yu, L. (2010). Decomposing the influencing factors of 642 industrial carbon emissions in Shanghai using the LMDI method. Energy, 35, 2505-2510

643 